\title{
REFLEXIONES SOBRE EL CONOCIMIENTO JURÍDICO
}

\author{
REFLECTIONS ON LEGAL KNOWLEDGE
}

Rogelio Zacarias Rodríguez Garduño ${ }^{1}$

RESUMEN: El presente trabajo tiene como propósito, brindar al lector un panorama claro sobre lo que es el conocimiento en general así como del conocimiento jurídico en lo particular, para dar paso a la utilidad que tiene el conocimiento jurídico en la vida diaria. Por lo tanto, a lo largo de las presentes disertaciones, me planteo como objetivo fundamental, tratar de explicar la forma en que se ha pensado con respecto a la utilidad del conocimiento de lo jurídico, mediante la reflexión de los siguientes cuestionamientos: ¿en qué momento se ha estudiado con profundidad el conocimiento jurídico? y ¿cuándo ha sido con superficialidad?

Palabras Clave: Conocimiento, conocimiento jurídico, utilidad, derecho, pensamiento jurídico.

ABSTRACT: The objective of this paper is to provide the reader an overview course about what knowledge in general as well as of legal knowledge in particular, to make way for the utility that has the legal knowledge in everyday life. Therefore, along the present lectures, I am raising as a fundamental objective, trying to explain the way in which it has been thought about the usefulness of legal knowledge, through the reflection of the following questions: When has studied in depth the legal knowledge? and when it has been with superficiality?

KEYWORDS: Knowledge, legal knowledge, utility, law, legal thinking.

Sumario: I. Introducción. II. El Conocimiento. III. Conocimiento Jurídico. IV . Corrientes Epistemológicas Jurídicas. V. Reflexiones sobre el Conocimiento Jurídico. VI. La crisis del Conocimiento en la Modernidad. VII. Reflexiones sobresalientes en torno a la actualidad del Conocimiento Jurídico. VIII. Conclusión. IX. Fuentes.

\footnotetext{
${ }^{1}$ Licenciado en Derecho con Mención Honorífica por la UNAM. Maestro en Derecho Procesal Constitucional y titular en la Especialidad de Amparo en la Universidad Panamericana; Doctor en Derecho por la misma institución.

Actualmente es Profesor de Tiempo Completo "C" en la Facultad de Derecho de la UNAM, en el programa de licenciatura y maestría. Correo electrónico: <rrodriguezg@ derecho.unam.mx>.

*Artículo realizado con la colaboración de Elizabeth de la Cruz González, egresada y actual tesista para la obtención del grado de la Licenciatura en Derecho.
} 


\section{INTRODUCCIÓN}

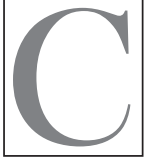

on el desarrollo de este trabajo, se espera que quienes tengan oportunidad de leerlo, hallen respuestas “claras” sobre la idea y la utilidad del conocimiento jurídico. La apreciación que tengo sobre esta importantísima materia, está íntimamente asociada a la profunda reflexión sobre el proceso del conocimiento en su adquisición, aplicación y constante actualización, razón por la que el conocimiento, al ser analizado, no puede partir de la nada, sino del formulado en las estructuras teóricas que sobre el conocimiento jurídico se han formulado y su reflexión filosófica.

Ante el planteamiento realizado, se abordara el estudio del conocimiento jurídico relacionado necesariamente con el conocimiento preexistente y ubicado singularmente en los postulados teóricos respecto del derecho, teniendo como objeto la extracción de las disposiciones epistémicas en la visión de quienes a lo largo del tiempo, se han postulado respecto del fundamento, fines y justificación del derecho; motivo por el que en el presente estudio, existe una coincidencia con cierta estructura del conocimiento jurídico, destacando que, por cuanto a nosotros constriñe, procuraremos para beneficio del lector, ocuparnos de los posicionamientos en torno a la construcción, presentación, divulgación y utilidad del conocimiento en relación con lo jurídico, razón por la cual cuando nos referimos a las corrientes epistemológicas ${ }^{2}$ - siguiendo la propuesta de título que presenta, si bien no desarrolla, el Doctor Rosalío López Durán-, por lo que estarán presentes la corriente positivista, naturalista y otras críticas que no se ubican necesariamente en alguna postura.

\footnotetext{
${ }^{2}$ López Durán, Rosalío, Metodología jurídica, México, D.F., IURE editores, 2002, p.123.
} 


\section{EL CONOCIMIENTO}

Para poder abordar el tema que nos ocupa en el presente trabajo, resulta necesario en primer lugar, señalar lo que entendemos por conocimiento en general, para que así, más adelante, podamos abordar lo que es el conocimiento jurídico en lo particular.

Conocimiento es definido en el Diccionario de la Real Academia Española como "entendimiento, inteligencia, razón natural”; así también como "noción, saber o noticia elemental de algo". ${ }^{3}$ Siendo así, tenemos entonces que el conocimiento son las nociones que se tienen respecto de un objeto, tema o situación en particular.

Para que este conocimiento pueda ser analizado, debemos tener claro que no puede partir de la nada, sino en todo caso, del formulado en las estructuras teóricas que sobre el conocimiento en lo general, y el conocimiento jurídico en lo particular, se han formulado.

Si se quiere estudiar el conocimiento, debe de existir previamente; es así que surge la pregunta: ¿de dónde proviene el conocimiento? Para dar contestación a este cuestionamiento tenemos las siguientes tres respuestas:

a) el conocimiento surge de los sentidos: este es un conocimiento subjetivo, tiene origen de la simple interpretación de la realidad de cada sujeto, por lo que carece de "certeza" y no puede ser generalizado. Podemos decir que es un conocimiento primitivo pues tiene su basamento en lo que cada uno "siente";

b) trasmisión empírica: encuentra su origen en la experiencia. Este sigue siendo un conocimiento subjetivo pues tiene su base en las vivencias que cada persona tiene y que van formando a su persona, y

c) el conocimiento que surge de la reflexión: el que se obtiene a través de la razón y el discernimiento mediante un proceso analítico que permite a las personas discriminar la utilidad de lo descifrado.

\footnotetext{
${ }^{3}$ Real Academia Española, [en línea], <http://dle.rae.es/?id=Fy2OT7b>, [consulta: 31 de mayo, 2018].
} 
A partir del conocimiento adquirido en estos planos, llega un momento en que el ser humano es capaz de detener su actuar mecánico para razonar, discernir y asumir posturas conformadas por un proceso analítico.

Por tanto, podemos indicar que el conocimiento no le es indiferente al ser humano, es decir, es una cuestión intrínseca a la naturaleza de éste, pues desde sus orígenes, la curiosidad de conocer el mundo ha acompañado al hombre y esto lo ha llevado a diferenciarse del resto de las especies animales, en otras palabras, conforme el ser humano evoluciona, de igual forma lo hace el conocimiento y el modo de adquirirlo.

No obstante, como prueba de lo anterior, tenemos la evolución del pensamiento científico, pues a lo largo de la historia hemos visto cómo ha cambiado, pasando de ser un conocimiento obtenido a partir de la reflexión y el pensamiento, a un conocimiento justificado por la divinidad, para finalmente ser un conocimiento cerrado dado por la rigidez de un sistema y "la certeza de las pruebas".

Es de este modo que se deja fuera del pensamiento científico todo aquel conocimiento que no se pueda encuadrar dentro de este sistema. Sin embargo, el hecho de que la ciencia moderna se sujete a un rígido sistema para la obtención del conocimiento, no constituye un obstáculo para generar otros sistemas con base en los cuales el ser humano pueda allegarse el conocimiento, pues como bien se postula en la corriente filosófica del racionalismo, elaborada por el pensador René Descartes, para que el hombre pueda allegarse del conocimiento es necesario que exista la razón.

En este punto resulta oportuno señalar, que el conocimiento que no tiene aplicación útil, es simplemente conocimiento muerto. Acorde con esta idea lo es el pensamiento que al respecto tiene Hegel, pues para él, el conocimiento debe de ser para beneficio del hombre y no para la trascendencia personal, es decir, para un fin egoísta. 


\section{CONOCIMIENTO JURÍDICO}

El conocimiento jurídico se encarga de describir, justificar y en esencia, de cuestionar la utilidad del mismo; sin embargo, cabe preguntarse ¿cuándo se ha estudiado con profundidad el conocimiento jurídico?

No podemos afirmar que el conocimiento jurídico ha sido analizado a profundidad, pues el estudio jurídico se ha centrado principalmente en la justificación, construcción y estructuración, dejando de manera superficial aspectos como su utilidad. Es por esta razón, que consideramos que uno de los requisitos que debe tener el conocimiento útil en el campo del derecho, sin importar la corriente a la que se encuentre suscrito, es que esté provisto de aceptación en las propuestas de prevención o solución a la problemática de los individuos y de su convivencia colectiva.

\section{CORRIENTES EPISTEMOLÓGICAS JURÍDICAS}

Las corrientes epistemológicas jurídicas han abordado temas relacionados con la construcción y justificación del conocimiento jurídico. Estas se han abordado en dos grandes grupos: el iusnaturalismo y el iuspositivismo, pero estas categorías nunca han sido definidas totalmente, pues aun dentro de ellas surgen nuevas corrientes que buscan dar respuesta a los cuestionamientos de los hombres por tratar de entender y comprender de donde viene el conocimiento en lo general y el jurídico en lo particular, así como por saber cuál es el fin último de estos. Es entonces que se abordara el estudio de las que, a nuestra consideración, son las dos grandes vertientes: el Iusnaturalismo y el Iuspositivismo.

\section{IUSNATURALISMO}

El termino de iusnaturalismo proviene de las raíces latinas ius (traducido como derecho) y naturale (relativo a la naturaleza), mientras que el sufijo -ismo suele significar "escuela" o "doctrina".

\footnotetext{
4 "Iusnaturalismo" [en línea], <http://etimologias.dechile.net/?iusnaturalismo>,
} 
Como principal postulado, sostiene que el derecho es connatural al ser humano, por lo que uno de los fines principales es la dignidad del ser humano y su respeto, esto con el objeto de garantizar el orden jurídico y lograr la plena realización de las personas.

Dicha doctrina tiene la firma creencia de la existencia de una ley superior a los hombres, la cual mantiene un orden preestablecido bajo el cual éstos deben de conducirse.

La doctrina del Iusnaturalismo tiene varias vertientes, cada una con su propia concepción de lo qué es el derecho natural y la ley natural, sin embargo, y a pesar de las diferencias que pueda haber dentro de estas vertientes, parece ser que todas parten de una idea común: el derecho vale y obliga como tal.

Es así que nos limitaremos a realizar un esbozo de algunas de las principales cosmovisiones a través de sus autores más relevantes, para poder desentrañar las visiones epistemológicas existentes en el derecho natural respecto del conocimiento jurídico.

\section{A) IUSNATURALISMO EN LA ANTIGUA GRECIA}

Por un lado tenemos el pensamiento de Platón, quien al hablar del derecho natural considera que lo relevante es poder identificar lo bueno de lo malo y lo justo de lo injusto, esto como resultado de los procesos intelectuales arrojados por la razón, mismos que a su vez se encuentran sometidos al poder divino. ${ }^{5}$ Es dable destacar que es indiferente al debate sobre la existencia del monoteísmo o politeísmo para construir su pensamiento.

Para Platón, la justicia como virtud se da en dos sentidos, el primero como el orden de las cosas y el segundo como el sitio que le corresponde a cada individuo en un grupo social de acuerdo a sus cualidades, por lo tanto, podemos decir que Platón es un naturalista dado que propone que la verdadera ley es aquella que más se acerca a la idea de la justicia, entendida en un sentido parecido al biológico,

[consulta: 25 de mayo, 2018].

${ }^{5}$ Cfr. López Durán, Rosalío, op. cit., nota 2, p.123. 
pues considera que los hombres deben inspirarse en el orden encontrado en la naturaleza para asignar determinados roles a las personas que conforman una sociedad de acuerdo a la virtudes que posean.

Por otro lado, el pensamiento de Aristóteles respecto del derecho se ocupa de la distinción entre la ley natural regida por el universo y las leyes específicas descriptivas que pretenden determinar lo verdadero o positivo, es decir, la diferenciacióndel derecho natural del derecho de los hombres. ${ }^{6}$

Por su parte, este autor se aparta de la divinidad pero sin dejar de lado la metafísica, pues la base del derecho natural no es la voluntad de los dioses, sino el orden Cósmico (el orden del Universo). En su obra Ética Nicomaquea, aborda los temas de la justicia y posteriormente la justicia política, de donde desprende dos elementos: la justicia legal y la justicia (considerando esto último como lo legal y lo igual). ${ }^{7}$

\section{B) IUSNATURALISMO DIVINO}

El iusnaturalismo divino tiene como base la idea de que el comportamiento del ser humano en la sociedad está regulado por un ente supremo (Dios), que impone límites al actuar humano a través de sus mandamientos. ${ }^{8}$

Sus máximos exponentes son San Agustín de Hipona y Santo Tomás de Aquino.

El pensamiento del primero de ellos tuvo como base la corriente del pensamiento cósmico del derecho natural. Para San Agustín, el derecho se presenta como la ley eternade la razón divina, es decir, es la voluntad de Dios quien manda y conserva el orden natural. De esta proviene la ley natural, que es aquella verdad revelada a los hombres, por ello nuestro autor señala que la ley humana nace del intelecto del legislador, pero para que sea justa y recta debe de estar

\footnotetext{
${ }^{6} \mathrm{Idem}$.

${ }^{7}$ Aristoteles, Ética Nicomaquea, México, Porrúa, 2016, p. 97.

${ }^{8}$ Cffr. López Durán, Rosalío, op. cit., nota 2, p.123.
} 
apegada a la ley natural y por tanto, a la ley eterna. La ley natural es inmutable pues es de carácter universal y está por encima de las circunstancias de tiempo y lugar, siendo así que la ley humana queda limitada a aquellas circunstancias relevantes para la marcha de la sociedad. De estos planteamientos se desprende que la utilidad que tiene el conocimiento humano, en el ámbito jurídico, es la de solucionar los problemas sociales.

Para Santo Tomás, el soporte de todo lo real y verdadero es la propia creación divina. El hombre, al poseer inteligencia, puede entender el orden y sentido de la creación. A partir de tales consideraciones, sostiene que Dios dota de libertad al hombre para que pueda elaborar normas de acuerdo a las condiciones en que se desarrolla. Razona al derecho como una obra justa, por lo que las manifestaciones jurídicas resultan instrumentos destinados al bien común y serán válidos siempre que se adecúen a lo justo; es decir, es la ley un mandato de la razón útil para el bienestar común, ${ }^{9}$ misma que es terrenalmente dictada por quien tiene el encargo del cuidado de la sociedad.

Considera la existencia de tres leyes, a sabed:

a) la ley eterna que proviene de la razón de Dios;

b) la ley natural, la cual se puede entender en dos sentidos: como regla y como medida; $y$

c) la ley humana: "es un cierto dictamen de la razón práctica" ${ }^{10}$ y se extiende solo a los seres racionales.

Finalmente, hace el señalamiento de que estas deben de tener cierta coherencia entre ellas, pues la ley humana que se contrapone a la ley divina o natural, no puede ser derecho. Para él, la utilidad del derecho no es nada más que el orden y el bien común.

\footnotetext{
${ }^{9}$ Cfr. Du Pasquier, Claude, Introducción al Derecho, Lima, Edinar, 1990, p. 184

${ }^{10}$ De Aquino, Santo Tómas, Tratado de la Ley, México, Porrúa, 2016, p. 12.
} 


\section{C) HUGO GROCIO}

Mención especial merece Hugo Grocio, pues es indiscutible que podemos ubicar a este autor como un antes y un después entre las corrientes epistemológicas relativas al escepticismo, empirismo, aún el racionalismo y una nueva posición asociada con el realismo. Su estructura para fundamentar el conocimiento y procurar las aproximaciones a la verdad, así como su contribución a la visión del orden jurídico están provistas de la razón natural, donde realizó un esfuerzo que le permitió, sin descalificar abiertamente "las razones y bases de Dios”, separar a las estructuras validas del conocimiento y del derecho, para dotarlas de una obra humana en sí misma, es por ello que representa un límite entre la concepción divina del derecho natural y el derecho natural sustentado fundamentalmente en la propia naturaleza humana.

Su pensamiento se basó principalmente en el de Aristóteles, de quien tomó la idea de la naturaleza social del ser humano, sustentando al conocimiento en sí mismo, al cual consideraba como "el fundamento inmediato del derecho natural" ${ }^{11}$ y de esa manera, conseguir la anhelada universalidad, dejando a la divinidad, creadora de la naturaleza, como el fundamento mediato. ${ }^{12}$ Dio un mayor énfasis a la naturaleza humana, postulando al derecho natural como la manifestación de la recta razón a partir de la cual muestra la naturaleza social de los hombres.

Una vez que logró separar el fundamento del orden y conocimiento de Dios de los hombres, propuso que con base en la naturaleza social y racional del hombre, se podía generar el principio pacta suntservanda, máxima donde puede ser justificada la autoridad de los gobiernos y de los pactos celebrados en el ámbito internacional.

Las posturas de Grocio influyeron en los llamados contractualistas, dentro de los cuales logramos ubicar a pensadores como John Locke y Jean-Jacques Rousseau.

\footnotetext{
${ }^{11}$ Hugo Grocio, Instituto de Investigaciones Jurídicas, Consultado el 19 de junio, de 2018, en <https://archivos.juridicas.unam.mx/www/bjv/libros/6/2698/11.pdf>.

${ }^{12}$ Cfr. Idem.
} 
John Locke concede un papel importante al conocimiento adquirido a través de los sentidos y la experiencia, atendiendo a que el ser humano es parte de su entorno natural. Justifica la existencia de la ley natural a través de cinco postulados importantes:

a) la ley natural existe porque está en todas partes; ${ }^{13}$

b) puede derivarse de la conciencia de los hombres; ${ }^{14}$

c) procede de la constitución misma del mundo, donde todas las cosas tienen un modo de existencia apropiado a su naturaleza;

d) ante la inexistencia de esta ley, no se podrían tener relaciones sociales; ${ }^{15}$ y e) la ausencia de esta ley es una falta de razón. ${ }^{16}$

Así pues, sostiene que la ley natural es innata a los seres humanos. ${ }^{17}$ Su conocimiento se adquiere por la experiencia y posteriormente es razonada por la conciencia. Por lo que una vez que se manifiesta la razón gobernada por la conciencia, nace la obligación de los hombres de ejercerla y, por ello, el Estado será el garante protegiendo el bien común.

Jean-Jacques Rousseau fue uno de los pensadores más influyentes en la transición de la estructura del conocimiento basado en el orden divino a un proceso del conocimiento racional, realista y crítico. Meditó acerca de que la única sociedad que puede considerase como natural es la familia, pero que dicho vinculo se disuelve cuando los hijos dejan de depender del padre y lo que los une es la voluntad, así pues, afirma que "la voluntad común es una consecuencia de la naturaleza del hombre". ${ }^{18}$

Para él, lo que propicia el contrato social es el cambio de un estado de naturaleza a un estado civil, donde existe la libertad civil y moral. Así mismo, señaló que "existe una justicia universal que

\footnotetext{
${ }^{13}$ Aristoteles, op. cit., nota 7, pp. 84 y 85.

${ }^{14}$ Ibidem, pp. 84-87.

${ }^{15}$ Ibidem, pp. 88 y 89 .

${ }^{16}$ Ibidem, p. 84.

${ }^{17}$ Cfr. Locke, John, Segundo tratado sobre el gobierno civil, trad. de Carlos Mellizo, Madrid, Alianza, s.f., p. 91-98.

${ }^{18}$ Jean-Jacques, Rousseau, Contrato social, trad. de Fernando de los Ríos, Espasa Calpe, 2007, p. 36.
} 
emana sólo de la razón”. ${ }^{19}$ Lo anterior llevó a que Rousseau señalara que los principales fines del sistema de legislación son la libertad y la igualdad.

D) PENSADORES MODERNOS

Para hacer el estudio de este apartado, se abordarán los postulados iusnaturalistas de Gustav Radbruch y John Finnis, que se caracterizan por alejarse del pensamiento divino y basarse en un derecho natural.

Gustav Radbruch sustenta su teoría en la naturaleza del hombre y la naturaleza de las cosas. En su obra Introducción a la Filosofía del Derecho, plantea la abstracción del pensamiento humano, por medio del cual creamos, aplicamos y modificamos el derecho, basados en diversos factores metafísicos y materiales que coexisten para que el pensamiento humano vislumbre una concepción del derecho.

Considera que el derecho tiene como fin la justicia, mismo que deriva de la libertad; para él la justicia deviene de la naturaleza del hombre y de las cosas. Asimismo, plantea que las relaciones de los hombres están en función de sus necesidades colectivas, dependiendo del tiempo, lugar y circunstancias en las que se encuentran, por lo que considera que el orden jurídico está basado en la cultura del hombre, de la que devienen valores supremos e innegables, que representan el bien y el mal.

Concibe al positivismo como un sistema a través del cual el derecho natural y aquellos valores mínimos de moralidad puedan ser exigibles bajo el esquema de un modelo garantista, por lo que la norma debe tener un carácter social, es decir, que por proponerse la realización de la justicia debe regular la convivencia humana.

De igual forma, sostiene la idea de tomar el conocimiento vulgar y complementarlo con la experiencia, para que a través de los procesos de reflexión, puedan acercarse a las soluciones, lo cual deberá ser confrontado para eliminar los estados de la natural duda humana.

\footnotetext{
${ }^{19}$ Ibidem, p. 65 y 66.
} 
Por su parte, John Finnis desarrolla lo que él llama la teoría de la Ley Natural, con la que busca identificar los bienes humanos que solamente pueden ser conseguidos con las instituciones de la ley humana, así como también establece bajo qué condiciones tales instituciones se justifican, además de las formas en que estas pueden ser defectuosas. ${ }^{20}$

Busca la practicidad del conocimiento, señalando que:

"una ciencia o teoría es práctica en el sentido más pleno, si ella es acerca de y dirigida hacia aquello que es bueno hacer, tener, obtener y ser [...] en el campo abierto a fines de la vida humana en su conjunto, por elecciones y actos $[. .$.$] y en vista de objetos, fines-bienes que proveen$ razones para obrar y otorgan sentido a la vida individual o grupal como un todo abierto a fines". ${ }^{21}$

Finnis sostiene que la relación que tiene el derecho positivo con la teoría del derecho natural es que ambas dependen para su existencia y validez de ciertos hechos sociales, ${ }^{22}$ hechos que corresponden a la naturaleza humana.

Los principios esenciales de la ley natural para él son:

a) los principios prácticos básicos: son los que manifiestan las formas básicas de realización humana, (fines o bienes a ser alcanzados por quienes se atrevan a cuestionarse qué es lo que deben hacer); y

b) los requerimientos metodológicos de la razonabilidad práctica: son los que nos van a permitir diferenciar el pensamiento práctico correcto del incorrecto.

Estos postulados explican la fuerza obligatoria de las leyes positivas, a pesar de que no puedan ser deducidas de estos principios.

${ }^{20}$ Cfr. Finnis, John, Ley natural y derechos naturales, trad. de Cristóbal Orrego Sánchez, Buenos Aires, Abeledoperrot, 2000, p. 37.

${ }^{21}$ Idem.

${ }^{22}$ Cfr. Finnis, John, op. cit., nota 20, p. 11. 


\section{IUSPOSITIVISMO}

En este apartado corresponde realizar el análisis epistemológico desde los postulados del iuspositivismo, una corriente más que se ha hecho presente en la historia de la humanidad con el propósito de dar - tentativamente- una respuesta a la utilidad del conocimiento jurídico, desde una perspectiva por momentos contraria a la planteada por el ya estudiado iusnaturalismo, pero que de manera preliminar podemos decir incurre en la mayor critica que le formula al derecho natural sobre todo de origen y fundamento divino, como es la presentación de verdades ciertas e indiscutibles de aceptación y observancia obligatoria, sin pasar por el esfuerzo epistemológico de encontrar la aproximación a la realidad autentica en la razón que mejor las ubique.

Esta corriente tiende a separar la moral y el derecho; postulándose fundamentalmente por medio de conceptos “objetivos” a través de la denominada ciencia jurídica, asemejada en su conformación y desarrollo al método experimental y demostrativo de las ciencias duras.

Al igual que con el derecho natural, existen varios teóricos que defienden esta postura, por lo que a continuación hablaremos de algunos de ellos, haciendo breves señalamientos en relación a sus posturas y aportaciones.

Augusto Comte fue un impulsor del pensamiento filosófico-positivista que habló de la jerarquía de las ciencias teóricas y de la formulación de la ley de los tres estadios.

Por cuanto hace a la jerarquía de las ciencias teóricas, estableció una división de las que llamó ciencias teóricas y prácticas, siendo que las primeras se subdividen en concretas (estudian los hechos específicos) y abstractas (se caracterizan por manifestar las leyes de la naturaleza que rigen a los hechos específicos).

Respecto a los estadios tenemos que estos son tres: primeramente el teológico, que se refiere a la creencia de los hombres en la creación divina; el metafísico es el segundo, que parte de la idea de que "las fuerzas abstractas, como la 'naturaleza' lo explicaban todo mejor 
que los dioses personificados", ${ }^{23}$ y el positivo, que se caracteriza por dejar de lado los dogmas de los estadios anteriores para creer ahora en lo que determina la ciencia.

Dicho lo anterior, podemos establecer que el positivismo desarrollado por Comte está basado en el discernimiento del hombre, mismo que da a conocer por medio de una teoría sobre el conocimiento que desentraña el sentido de la historia y su posición política ante la sociedad. Este positivismo lo interpreta a partir del conocimiento que se da por medio de datos o hechos verificables, mismo conocimiento que tendrá como características el ser cierto, sistemático y útil; aspira a conocer aquello que es posible saber a través del pensamiento.

Por cuanto hace a Jeremy Bentham, este autor analiza "la existencia de derechos naturales anteriores a la existencia del gobierno, sosteniendo que perderían su razón de ser en los países que ya hay un gobierno". ${ }^{24}$ Bentham solo admite la existencia del derecho positivo, en tanto que para él, lo derechos naturales con su característica de imprescriptibilidad, no corresponden con lo que acontecido en la realidad. Es por ello que para hacerle frente a la corriente del derecho natural, desarrolló el utilitarismo.

Es en su obra Introducción a los principios de moral y legislación, donde señala que "todo acto humano, norma o institución, deben ser juzgados según la utilidad que tienen, esto es, según el placer o el sufrimiento que producen en las personas”, ${ }^{25}$ para esto niega la existencia de ideas innatas, por lo cual entiende a la razón como una facultad experimental, calculadora capaz de descubrir las consecuencias de los actos.

\footnotetext{
${ }^{23}$ Ritzer, George, Teoría sociológica clásica, trad. de María Teresa Casado Rodríguez, España, Mc-Graw Hill, 1993 [en línea], <https://significanteotro.files.wordpress. com/2017/02/47832383-teoria-sociologica-clasica-george-ritzer.pdf $>$, [consulta: 13 de junio, 2018].

${ }^{24}$ Farrel, Martin D., El utilitarismo en la filosofia del derecho, IIJ-UNAM, [en línea], <https://archivos.juridicas.unam.mx/www/bjv/libros/8/3876/4.pdf>, [consulta: 08 de julio, 2018].

${ }^{25}$ Bentham, Jeremy, An Introduction to the Principles of Morals and Legislation, Oxford,Clarendon Press, 1907.
} 
Para él, tanto la figura del legislador como la del derecho son capaces de trasmitir el cálculo correcto, así como de educar en cuanto al deber ser y por lo tanto, ser medios adecuados para promover la reforma social. ${ }^{26}$ Por lo que los hechos humanos, las normas y las instituciones serán juzgados, valorando lo benéfico que resulten.

John Austin destaca la relación entre la jurisprudencia y la ciencia de la legislación, en tanto que todo conocimiento de lo que debe ser descansa en un conocimiento de antecedentes cognato genere, la ciencia de la legislación supone la jurisprudencia. Asume el nivel de conocimiento preexistente que da lugar al desarrollo del conocimiento reflexivo expresado en la jurisprudencia que se actualiza y las leyes que deben ir armonizándose con la realidad, al mismo tiempo que destaca que tales aportaciones deberán ser benéficas o útiles para el individuo o conjunto social.

Señala que es fundamental un estudio de los principios que constituyen el objeto de la jurisprudencia, pues así se disminuye la repugnancia con que la jurisprudencia es apreciada por algunos estudiantes. Ésta es el conocimiento empírico, sensorial, en suma la doxa, que permitirá que quienes se forman en esta disciplina, y a quienes aplican el derecho, depurar su apreciación del antecedente en el conocimiento para el caso concreto.

Destacan del concepto de derecho positivo los siguientes elementos:

a) los mandatos implican la manifestación del deseo de que algo sea hecho, combinado con la habilidad de imponer una sanción si no se cumple dicha voluntad;

b) las reglas son mandatos generales en contraste con los mandatos individuales o particulares;

c) el soberano es concebido como una persona (o un determinado grupo de personas) que

i) recibe una obediencia habitual por parte del pueblo; y que

\footnotetext{
${ }^{26}$ Cfr., Atienza, Manuel, Introducción al estudio del Derecho, México,D.F., Porrúa, 2005, p. 117.
} 
ii) él no obedece ninguna otra persona o institución; y

d) las sociedades políticamente independientes, por naturaleza, cuentan con un soberano.

Contrasta la norma jurídica positiva de la norma jurídica por analogía cerrada y de la norma por analogía remota, o sea, las reglas de la física. Así, razona a la norma jurídica como una regla establecida para la orientación de un ser inteligente por otro ser inteligente que tiene poder sobre el primero, las cuales se clasifican de acuerdo a las personas que las establecen.

No obstante, considera que el objeto de la jurisprudencia es descriptivo y no axiológico, esto es, hace referencia a su utilidad en el sentido de definir los principios que la integran, no así su valor, la cual pretende establecer criterios para la creación del derecho positivo.

Por otro lado, los grandes descubrimientos de la ciencia basada en la experimentación del siglo XX, llevaron a Hans Kelsen a proponer que la ciencia vista con el enfoque demostrativo también se podía aplicar al derecho, tal y como lo postuló en su Teoría Pura del Derecho. De esta manera, planteó alejar a la teoría del derecho de todos los elementos de valoración humana (moral o axiológica) en su aplicación o interpretación, proponiendo la pureza del derecho en el funcionamiento de sus enunciados duros dados en la ciencia del derecho.

Así, optó por justificar la autonomía del objeto del derecho, por lo que considera que esta no requiere de relaciones con otras ciencias como la sociología, psicología, etcétera. Aspiró a crear una ciencia jurídica dura e independiente de otras áreas del conocimiento.

Herber Lionel Adolphus Hart profundiza acerca de que los juristas, antes de "construir teorías”, deben examinar el lenguaje jurídico que se usa en la práctica del derecho, con el objetivo de lograr un genuino entendimiento del mismo, por lo que considera al derecho esencialmente como un fenómeno lingüístico. Además, señaló que uno de los primeros fines de la epistemología jurídica es ofrecer los fundamentos de las reglas jurídicas. 
Advierte que un sistema jurídico contiene elementos conectados con ciertos aspectos de la moral, compartiendo un vocabulario de obligaciones, derechos y deberes, así como ciertas prohibiciones. Asimismo, el autor da a entender que el derecho es una "rama” dela moral o de la justicia y que es su congruencia con los principios de moral o justicia-y no el hecho de que constituye un cuerpo de órdenes y amenazas-, lo que hace su "esencia".

Hart reconoce que existen algunas reglas conectadas con la naturaleza primigenia del ser humano, a las que denomina reglas primarias, que se caracterizan por atribuir acciones u omisiones a los sujetos, las cuales tienen el carácter de obligatorias. Frente a estas encontramos las reglas secundarias, las cuales otorgan potestades a los particulares o a las autoridades públicas para crear, modificar, extinguir o determinar los efectos de las reglas de tipo primario.

Considera tres tipos de reglas secundarias:

a) reglas de cambio, que confieren de la potestad para crear reglas primarias a los particulares y a los legisladores;

b) reglas de adjudicación, las cuales se conforman por las normas que se constituyen sobre el ejercicio de la función judicial; y

c) regla de reconocimiento, que es la que genera los criterios de validez del sistema jurídico, al ser esta la que determina que es el derecho.

\section{REFLEXIONES SOBRE EL CONOCIMIENTO JURÍDICO}

A continuación, se abordaran algunas de las propuestas de los pensadores que se han aventurado en compartir con el mundo sus ideas respecto de la utilidad del pensamiento jurídico, haciendo mención de que las posturas aquí tratadas no son las únicas o las mejores, sino en todo caso, son las que, para quien desarrolla el presente estudio, son las que representan mayor trascendencia en el mundo del derecho.

Así, primeramente tenemos a Georg Hegel, quien en su obra $L a$ fenomenología del espíritu, se encargó de desarrollar los conceptos de la 
dialéctica y del espíritu. Para él, la dialéctica es el método racional por el cual se explican los estadios que experimenta la sociedad, constituyendo dicho sistema la afirmación de una idea (tesis), la negación a la misma idea (antítesis) y una solución o conciliación de las anteriores (síntesis). Por otra parte, el espíritu es una verdad subjetiva que se manifiesta a través de los acontecimientos históricos, verdad subjetiva que tiene que irse explicando, pues estas forman parte de la evolución del conocimiento y de la sociedad. Dicho espíritu posee tres elementos:

a) subjetivo, que está caracterizado por los seres libres y cognitivos;

b) objetivo, caracterizado por las actividades libres en el mundo social y moral; $\mathrm{y}$

c) absoluto, porque representa la síntesis universal y total.

Es entonces que para este autor, el derecho es una manifestación de la voluntadlibre y racional de los hombres, volviéndose útil el derecho, cuando garantiza lalibertad de los hombres así como la convivencia de estos en sociedad.

Por lo que se refiere a Michel Foucault, en su obra Vigilar y Castigar: nacimiento de la prisión, parece explicarnos la génesis, naturaleza, desarrollo del conocimiento y estructuras en que se presenta el conocimiento jurídico, así como su eficacia, de una forma clara y contundente.

Para él, el derecho es una herramienta al servicio de la clase dominante, a través de la cual se pretende regular y controlar a los individuos en los aspectos social, económico y político, el cual va cambiando y reformulándose en atención a las necesidades culturales a través de su propio proceso histórico.

El derecho permite trazar las conductas que el poder dominante desee en las personas, este permea en todos los aspectos de su vida y concluye reflejándose en su conducta cotidiana, esperada y deseada por los creadores de normas -detentadores del poder-; es decir, la utilidad del conocimiento se presenta cuando se usa al derecho como una herramienta del poder, manejado y enfocado a ciertos 
fines en un espacio y contexto determinado, dicho de otro modo, cuando se usa para controlar a la sociedad en todos sus aspectos en un espacio y tiempo determinado.

Karl Raimund Popper, por su parte, realizó un estudio filosófico en relación a los métodos de investigación y el conocimiento científico en su obra La lógica de la investigación científica. Para él, la base fundamental y fin último del conocimiento científico es la utilidad que produce a los individuos y a las colectividades.

Asimismo, considera que el conocimiento científico tiende a ser universal, sin embargo, no sólo debe de admitir lo considerado "universalmente válido", sino que también debe de tomarse en cuenta el conocimiento sujeto a discernimiento, así como las aportaciones empíricas, ya que permiten tener una variedad de posibilidades en rededor de la forma en que es articulado el conocimiento.

En cuanto a su teoría del falsacionismo, toma como punto de partida la "demarcación”, con la cual intenta dilucidar y esclarecer los límites de la ciencia descriptiva y de la metafísica, así como de los objetos de estudio de las mismas. Es así que habla de la discriminación del conocimiento a partir de la veracidad o falsedad de este desde una estructura lógica, señalando en esto la imposibilidad de determinar la verdad o falsedad en construcciones de conocimiento diferentes a una expresión lógica formal.

Al hablar del conocimiento jurídico, la demarcación se hace presente cuando los enunciados normativos derivados de un procedimiento científico, tienen que ser objeto de un estudio de interpretación para poder aplicarlos al caso concreto, por ello nos apoyamos de la falsación, pues esta nos permite determinar cuáles son los que tienen una aplicación útil, permitiendo así que el sistema jurídico esté en un constante proceso de actualización. Por tanto, veríamos la utilidad del derecho en su propia aplicabilidad.

De entre las aportaciones más sobresalientes de Thomas Kuhn, resalta el estudio que realiza del tránsito de la metodología de la construcción del conocimiento riguroso de la comprobación -cien- 
cias duras- hacia el conocimiento sistematizado, permitiendo así, en el ámbito de las ciencias sociales, un margen de apreciación tanto en el proceso para formular el conocimiento como en su interpretación aplicativa.

Reflexionó acerca de que el conocimiento parte de la experiencia, ya que estasnos permitirán comprender por qué en ciertos momentos unas suposiciones han sido aceptadas antes que otras. ${ }^{27}$ Lo anterior lo ejemplifica al hablarnos de una comunidad científica que no podría practicar su oficio sin un conjunto de creencias recibidas que preparan la base del aprendizaje. En cuanto al ámbito del estudio jurídico, desarrolló un análisis crítico del derecho con base en el conocimiento preexistente del mismo, esto con el objetivo de permitir una posición analítica del derecho y de la utilidad de este a la sociedad, ofreciendo soluciones a los problemas que esta presenta.

No podemos olvidar que para la investigación jurídica, se debe partir de una investigación de hechos, ya que el objeto del estudio es la manifestación de la conducta humana en el entorno social para procurar el orden en las comunidades. Atendiendo a lo anterior, señalamos que la utilidad del conocimiento jurídico deriva de la investigación crítica y analítica que tiene éste respecto de la conducta humana en colectividad, a fin de preservar el orden social y solucionar los problemas existentes previniendo así los futuros.

Hans Georg Gadamer, considerado "el padre de la hermenéutica filosófica contemporánea”, ${ }^{28}$ reflexiona acerca de que el derecho ha de servir para comprender la norma jurídica y que esta debe ser interpretada desde su creación hasta su aplicación al caso en concreto. Lo anterior deriva del hecho de que, al ser el sistema jurídico un producto humano, este debe de actualizarse e ir evolucionando de acuerdo a las circunstancias sociales, económicas y políticas de la colectividad en un lugar y tiempo determinado.

\footnotetext{
${ }^{27}$ Cfr. KUHN, Thomas, La estructura de las revoluciones científicas, México, D.F., University of Chicago Prees, 1990, p. 13.

${ }^{28}$ AGUILAR, Luis Armando, "La hermenéutica filosófica de Gadamer", en Sinéctica, Revista Electrónica de Educación, México 2004 [en línea], <http://www.redalyc. org/articulo.oa?id=99815918009>, [consulta: 14 de junio, 2018].
} 
Considera también que, el orden jurídico formal no ha de ser cambiante frente a los problemas, sino que debe de aplicarse una interpretación singular, es decir, la interpretación es la que debe de aplicarse en atención a la solución de un caso en concreto.

Es entonces que, para comprender el conocimiento en lo general y el jurídico en lo particular, se debe entender primeramente la hermenéutica, ya que el conocimiento tiene que ser explicado, traducido o interpr tado, y en el caso del derecho esto se tiene que hacer al momento de aplicar e interpretar una norma jurídica, así como para la interpretación de los hechos sociales y los naturales, debiendo comprenderse el momento y situación concreta en el que se desarrollan, para tener así, una interpretación acorde a cada uno de los momentos en los que ha de ser aplicada.

Es por lo expresado con anterioridad, que Gadamer está en contra de que el jurista no tenga amplia libertad de interpretar y aplicar la norma jurídica.

Para nuestro autor, el derecho sirve para llegar a acuerdos, consensos y diálogos a través del entendimiento humano, del lenguaje, de la argumentación basada en la conciencia humana y cuya finalidad última es solucionar las problemáticas o conflictos propios de una sociedad o bien anticipar las soluciones preventivas que eviten la conflictiva.

A su vez, Jürgen Habermas se enfocó al estudio del derecho de una manera descriptiva y lo desarrolló con un enfoque filosófico, sosteniendo que la formación del orden jurídico y su aplicación es justificable y útil desde un plano epistemológico, ya que tiene un carácter social. ${ }^{29}$ Nos señala que el derecho formal debe de cumplir con dos condiciones:

a) establecer conductas predeterminadas y posibles, con el objeto de tener mayor certeza de que la conducta de quien debe seguirla sea apegada a lo planteado en la norma; y

${ }^{29}$ Cfr. Sobrevilla, David, La concepción Habermasiana del Derecho, Lima, Universidad Mayor de San Marcos, 2007, p. 565. 
b) la validez del orden jurídico depende de la aceptación de los sujetos a los que va destinado.

Debe de existir una congruencia en cuanto a lo planteado en la letra de la norma con lo que los receptores acepten. Dicha congruencia debe de ser justificada por una amplia argumentación interpretativa. En atención a lo anterior, resulta necesario que exista una adecuación del lenguaje jurídico para actualizar el desarrollo evolutivo del conocimiento aplicado del derecho.

Habermas considera que de la racionalidad débil, como lo es la moral, se hace necesario la aplicación e implementación de una normatividad jurídica para mantener una estabilidad social, por lo que el derecho complementa a la moral. ${ }^{30}$ En conclusión, sostiene que la utilidad del derecho se encuentra en la estabilidad que da a la sociedad con la fuerza de un orden jurídico que, mediante el Estado, trae un orden social.

\section{LA CRISIS DEL CONOCIMIENTO EN LA MODERNIDAD}

La forma en que se encuentra estructurado el conocimiento surgió en la modernidad -etapa intelectual y material del desarrollo humano- con la caída del sistema del orden basado en la "verdad por la razón de Dios”, bajo la premisa de dogmas como umbrales de lo que Dios permitía a los hombres conocer.

Esta forma cerrada del conocimiento científico postergó las reflexiones sobre el conocimiento por pretender la objetividad y rechazar las valoraciones humanas, surgiendo la necesidad -actual-de un conocimiento acorde a la realidad.

Siendo que la modernidad representa un cambio en la formulación del conocimiento y su justificación en el tránsito de Dios al hombre, lamentablemente no se concreta en la contención del cambio por estar sustentado en ideologías cerradas, que pregonan el desarrollo de la conciencia humana a partir de un conocimiento asu-

\footnotetext{
${ }^{30}$ Ibidem, p. 568 .
} 
mido por quienes son capaces de demostrarlo, en tanto no admite criticas sustantivas a su método.

Las estructuras del conocimiento de la modernidad han entrado en crisis porque prefieren a los postulados teóricos en sí mismos y desatienden a las necesidades humanas, por lo que se puede decir que está agotada y entonces estamos viviendo la etapa de la post-modernidad, un nuevo orden que se construye cotidianamente y donde el conocimiento y la filosofía juegan un papel muy relevante.

El conocimiento es consecuencia de un juego de signos que van produciendo significados sobre la realidad, que no extraen sino construyen lo real; se observa un desapego e inconformidad con un saber más preocupado en la consistencia lógica interna, que en su relación con lo real. ${ }^{31}$

Por lo que se refiere al conocimiento jurídico, se diseñó en la modernidad toda una teoría cientificista que utilizó el método demostrativo, buscando justificar el entendimiento del derecho a partir de su calidad de ciencia, olvidando su utilidad y naturaleza, por tanto, prescindiendo de la epistemología jurídica.

El modelo de la modernidad auto aplicado en el campo de lo jurídico, se dio a la tarea de predeterminar todas las posibles conductas humanas, codificarlas, lo que la convirtió en una forma mecánica antinatural de plantear y aplicar el orden jurídico, lo que lo ha conducido a una crisis indiscutible.

En el campo aplicado del derecho, se ha distorsionado la aplicación del pragmatismo y se ha confundido con conductas efectivistas que no buscan las soluciones de fondo, sino el reconocimiento inmediato que puede acarrear mayores problemas en el largo plazo, por ellos decimos que de lo que hemos prescindido en la praxis jurídica es de una adecuada interpretación del sistema, a partir de que asumimos la solución sólida del caso. Es por ello que no debe dejarse de lado la resistencia de quienes pretenden quedarse en la

\footnotetext{
1971.

${ }^{31}$ Cfr. Peirce, Charles, Mi alegato en favor del pragmatismo, Buenos Aires, Aguilar,
} 
modernidad por ofrecer la comodidad de imponer el conocimiento y el orden dado por la mera potestad que les da el poder público.

Resulta oportuno reconocer que quienes se encargan de aplicar el derecho -operadores jurídicos-, tienen consigo dos tipos de conocimiento:

a) el primero de ellos corresponde al que se allegan a través de la educación a nivel superior en el campo del derecho, y

b) el segundo pertenece al conocimiento que desarrollan por el ejercicio natural de la profesión, es decir, a la experiencia obtenida del poder judicial; el resultado de combinar ambos conocimientos permite que los operadores del derecho puedan dictar resoluciones y/o sentencias.

Como los jueces actúan y piensan bajo la misma directriz, se puede caer en un círculo vicioso de descomposición del derecho, que se ve acrecentado por la aparición de la aplicación mecánica sin el riguroso parámetro en los valores y principios, resultante de la adhesión a las vertientes epistemológicas que demandan de ofrecer soluciones útiles, novedosas para cada caso.

La resistencia a dejar el confort de la “resolución fácil”, que no exponga a la determinación correcta, pero quizá bajo el riesgo de la crítica o acaso más de la sanción, parece conducir a una corrupción o vicio en la aplicación del derecho que lo subordina a una actividad política del poder inmediato.

\section{REFLEXIONES SOBRESALIENTES EN TORNO A LA ACTUALIDAD DEL CONOCIMIENTO JURÍDICO}

En las siguientes líneas, se presentarán las reflexiones ocurridas en el mundo del derecho a partir de autores que comparten sus pensamientos, sin que para ellos searelevante ubicarlos dentro de un iuspositivismo o acaso del derecho natural. Esto llevóa algunos de ellos a autodenominarse "críticos", evitando ser encasillados en cualquier corriente de las dos ya descritas; más parece importarles el planteamiento de susconvicciones como genuinas aportaciones al desarrollo del conocimiento jurídico. 
Es así que comenzaremos con la insuficiencia en la transmisión de la propuesta del maestro Ronald Dworkin, por la incorrecta traducción de su obra Taking Rights Seriously, que ha sido traducida al castellano como Los derechos en serio, ${ }^{32}$ pues él propone contundentemente hablar en serio del derecho, lo que significa un reconocimiento a la incompleta labor del derecho aplicado.

En su teoría, Dworkin distingue los casos difíciles de entre los casos fáciles, en los que el operador jurídico se limita a aplicar una regla previa a un caso concreto. En loscasos difíciles, el juzgador para resolver un caso concreto, invoca directrices oprincipios que pueden ser de contenido moral o político.

Se refiere al positivismo como un sistema funcional para las normas propiamente dichas, a las cuales identifica como principios mismos que pueden estar reflejados en normas formalmente promulgadas- y directrices políticas.

El principio, en sentido genérico, lo utiliza para referirse a directrices, mientras que el principio en sentido estricto es para él un estándar que debe ser observado por ser una exigencia de la justicia, la equidad o la moralidad. La directriz, es concebida como un estándar que propone un objetivo que debe ser alcanzado, ya sea de carácter político, económico o social.

Hace también una distinción entre las normas jurídicas y los principios:

a) las normas están constituidas por un esquema que contiene las suposiciones jurídicas y su correlativa consecuencia;

b) los principios están enunciados de manera más abstracta y no tienen, antes del dictado de la resolución, una consecuencia jurídica en específico (por ejemplo, obligaciones o derechos).

Otra diferencia se encuentra en su forma de operar, las normas pueden tener reglas secundarias que resuelvan cuando se va aplicar una u otra norma en caso de conflicto. Los principios tienen una

\footnotetext{
${ }^{32}$ Cfr. Dworkin, Ronald, Los Derechos en serio, trad. de Marta Guastavino, Buenos Aires, Planeta- Agostini, 1993.
} 
dimensión de importancia o peso, en cuyo caso el juzgador tendrá que inferir su existencia y justificar su mayor importancia respecto de otro principio que también podría ser aplicable al caso concreto. Sostiene la teoría de que el derecho contempla principios y, por ende, su observancia es obligatoria para el juzgador; contra aquella que postula que el derecho no contempla los principios por lo que el juez sólo puede acudir a ellos en los casos que considere pertinente. Se mantiene en la visión epistemológica jurídica que asume como base del conocimiento jurídico la existencia de principios preexistentes al dictado de la resolución del juez.

Respecto a la posibilidad que tiene el juez de legislar materialmente en los casos novedosos donde no se pueda solucionar con la simple fórmula ordinaria que puede ser la subsunción de la norma, destaca que esto puede y debe ser posible, pues el juez se encuentra en una posición similar a la del legislador.

Distingue entre argumentos políticos y de principios, donde los primeros fundan la decisión con base en el beneficio que acarrearía a la generalidad y los ulteriores fundan su decisión en el respeto o aseguramiento de un derecho individual o de grupo, asumiendo que nos son absolutas ni exclusivas de cada uno de ellos.

A partir de la creación de un personaje ficticio llamado "Juez Hércules”, pretende dotar de una dimensión práctica su tesis para la solución de los casos difíciles.

Concluye que en los casos difíciles sí se pueden llegar a respuestas correctas, aunque sean controvertibles y en ocasiones no lleguen a satisfacer a todas las partes. Por lo anterior, es fácil deducir que crítica el postulado del positivismo que afirma la imposibilidad de llegar a respuestas correctas y únicas en casos difíciles.

Por su parte, Robert Alexy considera que la justificación, funcionamiento y utilidad del derecho, no se encuentran únicamente en lo que establece expresamente una norma emitida por un órgano con atribuciones para ello, sino que además de las normas, existen otro tipo de fundamentos denominados principios. Estos principios 
tienen una fuerte carga axiológica que influye en el sistema jurídico y así mismo son aplicados independientemente de si son o no contenidos en el texto legal, por lo que una norma positiva no puede (debe) violar los principios fundamentales.

Él nos plantea la existencia de dos tipos de normas respecto de las que hace una distinción sobre su aplicación: las reglas se aplican mediante la subsunción y los principios a través de la ponderación. Considera que los derechos humanos "solo tienen una validez moral [a la que] puede añadirse una validez de derecho positivo [...y] tales positivaciones nunca son respuestas definitivas". ${ }^{33}$

En la obra El concepto y la naturaleza del derecho, nos presenta una teoría entorno al derecho, sustentada en el cuestionamiento sobre lo que debe apreciarse como derecho, además de que considera que el conocimiento del derecho se encuentra dentro en la práctica jurídica. Pretende ofrecer un patrón epistemológico de razonamiento del derecho, apartado de los intereses políticos y de la concepción del mundo.

El derecho comprende un aspecto formalmente material y otro materialmente crítico, es decir que contiene una parte fáctica y otra aparentemente ideal, tomando aspectos del positivismo y del derecho natural, aunque prefiere denominarles aspectos no positivistas, por lo tanto, al intentar establecer una significación de derecho, hay que atender a aspectos sociales y a la idea de lo que el derecho debe ser.

Aborda el análisis de tres elementos principales para delimitar una noción de aproximación entorno al derecho: la legalidad, la eficacia social y la corrección material, estos nos permiten tener una estructura epistemológica del derecho, además de que nos ayudarán a una comprensión racional de su contenido, fines y realización práctica.

Él se postula por reconocer un papel diferente de los jueces, así lo plasma en las ideas centrales de la obra citada, en la cual deja ver que lo relevante en la reflexión epistemológica jurídica es atender la estructura a los derechos fundamentales del hombre.

\footnotetext{
${ }^{33}$ Alexy, Robert, "¿Derechos humanos sin metafísica?" Revista teoría y filosofía del Derecho, 2010.
} 
Gustavo Zagrebelsky en El Derecho dúctil. Ley, derechos, justicia, ${ }^{34}$ nos indica que la noción y manifestaciones del derecho se encuentran relacionadas con la manera en que la estructura jurídica ha evolucionado, lo que significa su armonización ante una realidad cambiante.

Zagrebelsky postula la existencia de un problema en la relación del derecho con las características particulares de la sociedad (características étnicas, religiosas, políticas). Es entonces que para él, las normas jurídicas no son meras expresión de intereses particulares, enumeración de principios universales e inmutables e impuestas por el legislador y que los demás han de acatar.

Afirma que el derecho constituye un conjunto de reglas jurídicas, normas y principios constitucionales que permiten la convivencia armónica entre los diferentes integrantes de la sociedad, mismos que deberán en todo momento materializar la aplicación y prevalencia de la justicia en las decisiones de los operadores jurídicos.

En su opinión, el derecho es la forma más adecuada que nos hemos dado para combatir la arbitrariedad o el abuso del poder. Entonces, la propuesta de Zagrebelsky parece circunscribirse en construir un estado constitucional justo y dinámico, que debe adecuarse a los cambios que enfrenta la sociedad, evitando en la medida de lo posible, que el orden jurídico formal sea obsoleto y por tanto, no resuelva la problemática que se presenta en la sociedad, frente a los vertiginosos e inusitados cambios que experimenta.

Como apoyo a lo anterior, resulta beneficiosa la descripción de Zagrebelsky sobre el derecho compuesto por reglas y por principios. Nos explica con razonable claridad la importancia y alcances de la Constitución en los estados constitucionales en la actualidad.

Zagrebelsky presenta también una solución entre la teoría y la práctica, entre lo abstracto del derecho y su aplicación en la vida cotidiana, convirtiéndose en elemento controlador del abuso del poder en todas sus acepciones; plantea la existencia de un problema

\footnotetext{
${ }^{34}$ Zagrebelsky, Gustavo, El Derecho dúctil. Ley, derechos y justicia, trad. de Marina Gascón, Madrid, Trotta, 1997.
} 
en la relación del derecho con las características particulares de la sociedad, como son sus características étnicas, religiosas, políticas, cultural, entre otras.

En cuanto a John Finnis, en la obra Natural law and natural rights, nos señala que el derecho requiere ser valorado y comprendido, para ello exige el uso de la razón práctica, que distingue entre el bien y el mal. Al realizar este análisis, encontraremos las formas en las que se ha comprendido el lenguaje en que se expresa el derecho, por lo que se tienen que buscar los elementos comunes, para ello propone lo siguiente:

1) Atender a un fin práctico: identificar los elementos descriptivos de los conceptos de derecho, atendiendo a los fines que cada uno determina; para tales elementos descriptivos no valorativos que proponen cada autor, Finnis propone igualar lo "importante y lo significativo" de la experiencia para su propia hipótesis estudiada en la obra que nos ocupa;

2) Elección del caso central y del significado focal: debe identificarse en la sistemática composición de significados de los términos a emplear en las teorías sin perder el principio o fundamento racional de este cumulo de significados. El caso periférico es un ejemplo, una versión adulterada del caso central, o hasta actitudes humanas formadas por referencia al caso central;

3) Elección del punto de vista: desde una perspectiva práctica, es el pensamiento práctico respecto de lo que debemos hacer; lo que conocemos como razonabilidad practica es razonabilidad al ocuparse y resolver obligaciones, al escoger y llevar a cabo proyectos, y en general, al actuar.

Ejemplifica al "conocimiento" como un valor básico y lo distingue de dos formas:

a) curiosidad, conocimiento buscado por sí mismo; e

b) instrumental, conocimiento útil en cuanto a la búsqueda de un objetivo.

Para Finnis, el conocimiento es una cosa buena que vale la pena poseer por sí misma, y no sólo por utilidad, el conocimiento es en 
sí mismo un bien. Adicionalmente nos dice que las personas que han tenido el impulso por conocer y la curiosidad por la verdad, son quienes pueden entender mejor el coste del conocimiento.

El escepticismo sobre este valor básico es indefendible, razón por la cual el autor toma las posturas de un análisis lógico de las premisas que pueden existir en contra del valor básico del conocimiento, estas son:1) todos los argumentos planteados por un escéptico va a refutarse a sí mismo, atacando al argumento, no al valor del bien básico; 2) las proposiciones que se refutan a sí mismas por ser contradictorias; y 3) las proposiciones que no pueden ser coherentemente afirmadas, porque son inevitablemente falseadas al afirmarlas de cualquier modo.

Por ello, entra al estudio de la premisa "el conocimiento no es un bien”, siendo esta una auto-refutación operacionalmente, pues quien formula esta afirmación se encuentra comprometido de que no cree que vale la pena hacer esta afirmación, y lo que realmente vale la pena es hacerla verdad, pero el sentido de su afirmación primaria era que la verdad no es un bien que vale la pena buscar o conocer, cayendo en una creencia formalmente contradictoria.

En ese sentido, se hace necesario plantear si existe una naturaleza humana como tal y cuáles son sus características.

\section{CONCLUSIÓN}

Uno de los mayores objetivos que se ha buscado en el desarrollo del presente trabajo, es compartir con el lector algunas ideas en torno a la utilidad del conocimiento jurídico, sin el ánimo de afirmar que, las reflexiones aquí mostradas, constituyen de forma alguna una verdad absoluta. Corresponderá en todo caso al lector, decidir cuál de estas reflexiones es válida y cuál deberá someterse a un juicio valorativo para determinar el beneficio que esta pueda brindarle.

Y es que, sin duda alguna, el pretender hablar acerca de cuál es la utilidad del conocimiento jurídico, nos lleva a profundizar en las corrientes que a lo largo de los años se han desarrollado con 
la intención de dar respuesta a este planteamiento, de ahí que se realizara un estudio que va desde los antiguos griegos hasta John Finnis, pasando por Hans Kelsen y Ronald Dworkin. No obstante, pareciera que la respuesta al planteamiento que ha dado origen a la presente exposición, no es aun completamente satisfactoria, ya que existen razones que van a conducir las réplicas que se presenten por distintos caminos.

Un hecho que ilustra lo anterior, podría recaer en la forma en la que adquirimos el conocimiento (en general). No todos los hombres alcanzan un aprendizaje de la misma forma, algunos lo consiguen a través de la interpretación de la realidad mediante los sentidos, razón que es nada suficiente para afirmar que, a modo de ejemplo, lo que afirmamos que dijo Gustav Radbruch, sea verdaderamente lo que él manifestó en su momento, mientras que por el contrario, otros se allegan del conocimiento mediante un proceso de reflexión, que dicho esta de mas, tampoco se realiza de la misma forma ni con el mismo grado de exhaustividad.

Por si fuera poco, tampoco se pude pasar por alto que, quizá aquellos que a lo largo de la historia se han dedicado a reflexionar en torno a la utilidad del conocimiento jurídico, podrían influir en quienes deseen proporcionar una respuesta satisfactoria a lo antepuesto, siendo probable que, la utilidad del conocimiento jurídico dependa de los intereses de quien ostenta ese conocimiento, más allá de su verdadera utilidad. Es así que los operadores jurídicos bien se ubicarían en el supuesto anterior, dado que algunos de ellos son capaces de empeñarse en realizar acciones que obstaculicen la edificación de una base sólida en cuanto a la utilidad del conocimiento jurídico, mientras que otros, por el contrario, realizarían su mejor esfuerzo para que dicha base sea construida de la mejor manera para beneficio de la sociedad.

Ahora bien, otro aspecto en el cual se debe prestar suma atención, es en la falacia respecto de que el mundo jurídico constituye un mundo diferente. En un primer momento es dable que se crea 
esto en tanto que, en apariencia, los operadores jurídicos "han elaborado" un objeto de estudio que exige ser analizado con su propio lenguaje -que en ocasiones pasa por inasequible a quienes difieren de este mundo jurídico-; por el contrario, existen aquellos que consideran que el conocimiento jurídico sólo se ha encargado de teorizar, mas no de resolver las situaciones que acontecen en el mundo real, pues para ellos, los teóricos jurídicos se encargan de profundizar en los problemas existentes y no de proponer soluciones reales y efectivas.

Más si de algo aún se puede debatir, es sobre el hecho de que antes de reconocer los aciertos, quizá erróneamente se ha optado por enaltecer las fallas de quienes se han atrevido a hondar en la utilidad del conocimiento, originando un retroceso en el conocimiento jurídico y su utilidad.

Los enunciados anteriores podrán -o no- resultar ciertos para quien lea estas líneas, pero lo cierto es que el derecho ha buscado dar solución a situaciones acontecidas en la realidad, con el objetivo de salvaguardar el bien de la sociedad. Si éste ha fallado, corresponderá a los estudiosos del derecho, así como a los operadores jurídicos y en general, a todo aquel que se vea inmerso en el derecho, hallar el problema y brindar una solución al mismo, porque la obligación adquirida consigo mismos y con la sociedad, les exigiría no solo buscar aparentes soluciones, sino brindar respuestas claras y objetivas que satisfagan a la colectividad, para poder cambiar el paradigma existente alrededor del conocimiento jurídico, y de esta manera, demostrar cuál es la verdadera utilidad del conocimiento jurídico. 


\section{FUENTES}

1. Bibliografia

ALEXY, Robert, “¿Derechos humanos sin metafísica?" en Revista teoría y filosofia del Derecho, 2010.

ARISTOTELES, Ética Nicomaquea, México, D.F., Porrúa, 2016.

ATIENZA, Manuel, Introducción al estudio del Derecho, México, Porrúa, 2005.

BENTHAM, Jeremy, An Introduction to the Principles of Morals and Legislation, Oxford,Clarendon Press, 1907.

DE AQUINO, Santo Tómas, Tratado de la Ley, México, Porrúa, 2016.

DU PASQUIER, Claude, Introducción al Derecho, Lima, Edinar, 1990.

DWORKIN, Ronald, Los Derechos en serio, trad. de Marta Guastavino, Buenos Aires, Planeta- Agostini, 1993.

FINNIS, John, Ley naturaly derechos naturales, trad. de Cristóbal Orrego Sánchez, Buenos Aires, Abeledoperrot, 2000.

JEAN-JACQUES, Rousseau, Contrato social, trad. de Fernando de los Ríos, 12a edición, Espasa Calpe, 2007.

KUHN, Thomas, La estructura de las revoluciones científicas, México, University of Chicago Prees, 1990.

LOCKE, John, Segundo tratado sobre el gobierno civil, trad. de Carlos Mellizo, Madrid, Alianza.

LÓPEZ DURÁN, Rosalío, Metodología jurídica, México, D.F., IURE editores, 2002.

PEIRCE, Charles, Mi alegato en favor del pragmatismo, Buenos Aires, Aguilar, 1971.

SOBREVILLA, David, La concepción Habermasiana del Derecho, Lima, Universidad Mayor de San Marcos, 2007. 
ZAGREBELSKY, Gustavo, El Derecho dúctil. Ley, derechos y justicia, trad. de Marina Gascón, Madrid, Trotta, 1997.

\section{ELECTRÓNICAS}

"Iusnaturalismo" [en línea], 〈http://etimologias.dechile.net/?iusnaturalismo〉, [consulta: 25 de mayo, 2018].

AGUILAR, Luis Armando, "La hermenéutica filosófica de Gadamer", en Sinéctica, Revista Electrónica de Educación, México 2004 [en línea], <http://www.redalyc.org/articulo.oa?id=99815918009>, [consulta: 14 de junio, 2018].

FARREL, Martin D., El utilitarismo en la filosofia del derecho, IIJ-UNAM, [en línea], <https://archivos.juridicas.unam.mx/www/bjv/libros/8/3876/4.pdf>, [consulta: 08 de julio, 2018].

Hugo Grocio, Instituto de Investigaciones Jurídicas, Consultado el 19 de junio, de 2018, en <https://archivos.juridicas.unam.mx/www/bjv/libros/6/2698/11.pdf>.

Real Academia Española, [en línea], 〈http://dle.rae.es/?id=Fy2OT7b>, [consulta: 31 de mayo, 2018].

RITZER, George, Teoría sociológica clásica, trad. de María Teresa Casado Rodríguez, España, Mc-Graw Hill, 1993 [en línea], <https://significanteotro. files.wordpress.com/2017/02/47832383-teoria-sociologica-clasica-george-ritzer.pdf>, [consulta: 13 de junio, 2018]. 